\title{
A Prospective, Multi-Center, Double-Blind, Randomized Study to Evaluate the Efficacy and Safety of the Synthetic Bone Graft Material DBM Gel with rhBMP-2 versus DBM Gel Used during the TLIF Procedure in Patients with Lumbar Disc Disease
}

\author{
Seung-Jae Hyun, ${ }^{1}$ Seung Hwan Yoon, ${ }^{2}$ Joo Han Kim, ${ }^{3}$ Jae Keun Oh, ${ }^{4}$ Chang-Hyun Lee, Jun Jae Shin, ${ }^{6}$ Jin Kang, ${ }^{6}$ Yoon Ha ${ }^{7}$ \\ Department of Neurosurgery, Spine Center, Seoul National University Bundang Hospital, Seoul National University College of Medicine, Seongnam, Korea \\ Department of Neurosurgery, ${ }^{2}$ Inha University College of Medicine, Incheon, Korea \\ Department of Neurosurgery, ${ }^{3}$ Korea University Guro Hospital, Korea University College of Medicine, Seoul, Korea \\ Department of Neurosurgery, 4 Spine Center, Hallym University Sacred Heart Hospital, Anyang, Korea \\ Department of Neurosurgery, ${ }^{5}$ Seoul National University Hospital, Seoul National University College of Medicine, Seoul, Korea \\ Department of Neurosurgery, ${ }^{6}$ Yongin Severance Hospital, Spine and Spinal Cord Institute, Yonsei University College of Medicine, Yongin, Korea \\ Department of Neurosurgery, ${ }^{7}$ Spine and Spinal Cord Institute, Yonsei University College of Medicine, Seoul, Korea
}

Objective : This study is to evaluate the efficacy and safety of demineralized bone matrix (DBM) gel versus DBM gel with recombinant human bone morphogenetic protein-2 (rhBMP-2) used in transforaminal lumbar interbody fusion (TLIF).

Methods : This study was designed as a prospective, multi-center, double-blind method, randomized study. All randomized subjects underwent TLIF with DBM gel with rhBMP-2 group (40 patients) as an experimental group or DBM gel group (36 patients) as a control group. Post-operative observations were performed at 12,24 , and 48 weeks. The spinal fusion rate on computed tomography scans and X-rays films, Visual analog scale pain scores, Oswestry disability index and SF-36 quality of life (QOL) scores were used for the efficacy evaluation. The incidence rate of adverse device effects (ADEs) and serious adverse device effects (SADEs) were used for safety evaluation.

Results : The spinal fusion rate at 12 weeks for the DBM gel with rhBMP-2 group was higher with $73.68 \%$ compared to $58.82 \%$ for the DBM gel group. The 24 and 48 weeks were $72.22 \%$ and $82.86 \%$ for the DBM gel with rhBMP-2 group and $78.79 \%$ and $78.13 \%$, respectively, for the DBM gel group. However, there were no significant differences between two groups in the spinal fusion rate at 12,24 , and 48 weeks post-treatment ( $p=0.1817, p=0.5272, p=0.6247$ ). There was no significant difference between the two groups in the incidence rate of ADEs ( $p=0.3836)$. For ADEs in the experimental group, 'Pyrexia' $(5.00 \%)$ was the most common ADE, followed by 'Hypesthesia', 'Paresthesia', 'Transient peripheral paralysis', 'Spondylitis' and 'Insomnia' (2.50\%, respectively). ADEs reported in control group included 'Pyrexia', 'Chest discomfort', 'Pain', 'Osteoarthritis', 'Nephropathy toxic', 'Neurogenic bladder', 'Liver function analyses' and 'Urticaria' (2.86\%, respectively). There was no significant difference between the two groups in the incidence rate of SADEs ( $p=0.6594)$. For SADE in the experimental group, "Pyrexia' and 'Spondylitis' were 2.50\%. SADE reported in the control group included 'Chest discomfort', 'Osteoarthritis' and 'Neurogenic bladder'. All SADEs described above were resolved after medical treatment.

Conclusion : This study demonstrated that the spinal fusion rates of DBM gel group and DBM gel with rhBMP-2 group were not significantly different. But, this study provides knowledge regarding the earlier postoperative effect of rhBMP-2 containing DBM gel and also supports the idea that the longer term follow-up results are essential to confirm the safety and effectiveness.

Key Words : Spinal fusion · Double-blind method · Recombinant human bone morphogenetic protein-2 - Visual analog scale · Safety.

- Received : December 2, 2020 •Revised : January 4, 2021 •Accepted : January 27, 2021

- Address for reprints : Yoon Ha

Department of Neurosurgery, Spine and Spinal Cord Institute, Yonsei University College of Medicine, 50-1 Yonsei-ro, Seodaemun-gu, Seoul 03722, Korea

Tel : +82-2-2228-2151, Fax : +82-2-393-9979, E-mail : hayoon@yuhs.ac, ORCID : https://orcid.org/0000-0002-3775-2324

This is an Open Access article distributed under the terms of the Creative Commons Attribution Non-Commercial License (http://creativecommons.org/licenses/by-nc/4.0) which permits unrestricted non-commercial use, distribution, and reproduction in any medium, provided the original work is properly cited. 


\section{INTRODUCTION}

Intervertebral Disc Degeneration with associated spinal stenosis can cause back and lower limb pain in the patient. In patients who do not respond to non-surgical therapy, the most commonly performed surgical procedures for treating this condition are lumbar decompression and spinal joint arthrodesis. Surgery is required for the treatment of severe symptoms of degenerative disc degeneration and spinal fusion surgery is performed as the representative surgical method.

The bony fusion decreases mechanical stimuli to the outer annulus fibrosus and the pain nerve ending of the posterior longitudinal ligament by inducing bone fusion in an affected disk, thereby reducing the patient's symptoms. The main types of fusion surgery include transforaminal lumbar interbody fusion (TLIF), posterior lumbar interbody fusion (PLIF), posterolateral fusion, anterior lumbar interbody fusion (ALIF), and global fusion performed concomitantly with the aforementioned procedures ${ }^{7,19,22)}$.

Among these fusion surgical procedures, the TLIF is an approach introduced by Harms in 1982 and is a modified PLIF technique. It has been introduced to overcome disadvantages and complications associated with the PLIF and ALIF. In other words, since the bone graft is inserted into the disc space from the outside much further in the TLIF procedure than in the PLIF procedure, possible risks or limitations may be overcome by reducing traction of the nerve root or dura mater. The ALIF approach has a risk of approach related complication such as major haemorrhage due to visceral injury in the abdomen. Therefore, the use of TLIF is gradually increasing. During the TLIF procedure, bone graft materials that are inserted into the disc space after removal of disc fragments include autograft and allograft, and an artificial cage is filled with autograft or allograft ${ }^{3,17,21,34)}$.

Urist and Strates $^{36)}$ has revealed that a protein extracted from organic substances of the bone has a bone formation-inducing activity. It has been reported that numerous types of local growth factors are involved in bone healing and fusion of bone graft since the protein was named by Urist and Strates $^{36)}$ as the bone morphogenetic protein (BMP). BMPs have been classified into at least 20 protein growth factor family or superfamily members based on the similarity in their composition. Among BMP family members, BMP-2 have been known to have almost similar functions and activities in the course of bone formation ${ }^{13,23,30)}$. BMPs clinically used in spinal fusion or bone induction include recombinant human bone morphogenetic protein-2 (rhBMP-2). The first clinical study using rhBMP-2 has been initiated under supervision of Food and Drug Administration in 1996. According to a clinical study where the cage filled with either a type 1 collagen sponge combined with rhBMP-2 or autograft was used during the ALIF procedures, the fusion rate was $100 \%$ for the rhBMP-2 group and $95.6 \%$ for the autograft group ${ }^{5}$. Especially in the rhBMP-2 group where an intervertebral body fixation device was not used, the best results were observed along with a higher fusion rate ${ }^{1)}$. In the other published previous clinical studies $^{18,24,26,28,39)}$, the 1-year-fusion rate of the patients who had rhBMP-2-implants in the PLIF or TLIF approach was 73\% to 78\%.

The bone fusion rate is one of the main variables that can evaluate the performance of bone graft materials. Various carrier candidates have been investigated for the application of rhBMP-2. A successful candidate carrier should provide vascular and cellular invasion to favor osteo-inductive by the growth factor ${ }^{4)}$. Demineralized bone matrix (DBM) is based on allogeneic bone and is produced through demineralization $^{14,16)}$. It is osteo-conductive and osteo-inductive due to the fact that bony tissue contains various growth factors ${ }^{31)}$. DBM is used for example in spinal fusions ${ }^{15)}$. It functions as a scaffold to support bone regeneration, but can also be used as a carrier for cells or different kinds of growth factor ${ }^{2}$. When DBM act as a carrier, it combines the properties of the grafting material as delivered substances. A few other studies have found that DBM is a suitable carrier for rhBMP- $2^{27)}$. The mechanism underlying these useful effects of DBM as a carrier for rhBMP-2 is not clear; however, it seems that the collagenous substrate that remains after hydrochloric acid extraction of the mineral fraction ${ }^{35)}$ might provide a sustained pattern of release of the osteo-inductive protein ${ }^{38)}$ and serve as a scaffold for the proliferation and differentiation of osteoprogenitor cells. We thought DBM with rhBMP-2 would act as an osteoinductive scaffold that enhances spinal bone fusion.

To the best of our knowledge, no randomized clinical trials of the utility of DBM gel with rhBMP-2 for interbody fusion have been performed.

This clinical study was conducted in a multi-center, perspective, randomized design to comparatively evaluate the efficacy and safety of DBM gel with rhBMP-2 versus DBM gel used during the TLIF procedure in patients with lumbar disc disease 


\section{MATERIALS AND METHODS}

\section{Study design}

This clinical study was designed as a perspective, multicenter, double-blind, randomized study and was reviewed and approved by the Institutional Review Board (IRB) at each of the seven study centers in the Republic of Korea (Seoul National University Bundang Hospital IRB No. E-1505/298-002, Inha University College of Medicine IRB No. 2015-02-003, Korea University Guro Hospital IRB No. 2014GR0679, Korea University Guro Hospital IRB No. 2015GR0722, Hallym University Sacred Heart Hospital IRB No. 2014-S005, Soonchunhyang University Bucheon Hospital IRB No. 2015-07-039, Yonsei University College of Medicine IRB No. 1-2013-0070). The present study was conducted with the approval (IND No. 424) of the Ministry of Food and Drug Safety Association.

Patients with lumbar disc disease in this study in writing underwent screening tests. Only subjects who met all inclusion and exclusion criteria were randomized in either DBM gel with rhBMP-2 (RAFUGEN ${ }^{\mathrm{TM}}$ BMP-2; Cellumed Co., Ltd., Seoul, Korea) as an experimental group or DBM gel (RAFUGEN $^{\mathrm{TM}}$ DBM; Cellumed Co., Ltd.) as a control group. This clinical study is a double-blind trial and is automatically randomized in an electronic system to prevent bias that may be involved in the allocation of each experimental group and control group. Subjects were assigned to the experimental group or control group by the allocation code provided by the randomization program prior to the procedure when the subject was satisfied with the subject selection criteria.

The DBM gel was mixed with DBM powder, porcine collagen gel, and carboxymethyl cellulose (CMC). The DBM gel with rhBMP-2 was mixed with DBM powder which is conjugated with rhBMP-2, porcine collagen gel, and CMC. The rhBMP-2 agent (Cellumed Co., Ltd.) was prepared using human BMP-2 expressing Chinese Hamster Ovary cell line. The rhBMP-2 is homo-dimer, composed of two monomers with 114 amino acids, and is a $31 \mathrm{kDa}$ glycoprotein linked by one interchain disulfide bond.

\section{Patient numbers}

The purpose of the clinical study is to compare fusion rate between two groups at 12 weeks and show that DBM gel with rhBMP-2 is superior to DBM gel. From the study of Mummaneni et al. ${ }^{26)}$, the fusion rate at 12 weeks in the test group treated with iliac crest bone grafting (ICBG)+BMP was $57.14 \%$, and the fusion rate at 12 weeks in the test group treated with ICBG was $15.79 \%$. Therefore, in this study, the fusion rate up to 3 months was $57 \%$ in the test group treated with ICBG+BMP and fusion rate of the control group treated with ICBG at 3 months was assumed to be $16 \%$. Along with the above assumption, the significance level is 0.05 for a two-sided test, $95 \%$ power (power correction), and the minimum number of subjects for $1: 1$ assignment is as follows :

$$
\begin{aligned}
n_{2} & =\frac{\left(Z_{1-\alpha / 2}+Z_{l-\beta}\right)^{2}\left[\frac{p_{T}\left(1-p_{T}\right)}{k}+P_{C}\left(1-p_{C}\right)\right]}{\left(\left(p_{T}-p_{C}\right)\right)^{2}} \\
& =\frac{(1.96+1.645)^{2}\left[\frac{0.57(1-0.57)}{1}+0.16(1-0.16)\right]}{((0.57-0.16))^{2}} \\
& \approx 30 \\
& \mathrm{n}_{1}=\mathrm{kn}_{2}=30
\end{aligned}
$$

where, $P_{T}$ : fusion rate of test group, $P_{C}$ : fusion rate of control group, $K$ : allocation ratio.

Therefore, the minimum number of subjects required according to the calculation is 30 subjects per group (a total of 60 subjects), and 38 subjects per group (a total of 76 subjects) will be registered considering the dropout rate of $20 \%$.

\section{Inclusion and exclusion criteria}

Patients with pain attributable to lumbar disc disease in the TLIF procedure was scheduled participated in this study and underwent screening tests. The inclusion and exclusion major criteria were used to select subjects eligible for participation in this study (Table 1). Only potential subjects who met all of the above inclusion criteria and who do not meet any of the exclusion criteria were enrolled in this study.

\section{Surgical procedures}

All randomized subjects underwent the TLIF in accordance with the following procedures. After removal of the lamina, facet joints, and transverse processes, pedicle puncture was performed, and then a spinal internal fixation system was inserted using a pedicle finder. A posterior decompressive procedure was followed by a unilateral radical facetectomy. At this time, the intervertebral body fixation device was inserted and exposed parallel to the endplate, and then the posterior lipping endplates were removed using a small osteotome. A 
Table 1. Demographic information and baseline characteristics

\begin{tabular}{|c|c|}
\hline Inclusion criteria & Exclusion criteria \\
\hline $\begin{array}{l}\text { - Male and female subjects aged } 20 \text { to } 80 \text { years } \\
\text { - Patients with } 1 \text { or } 2 \text { consecutive degenerative disc disease between } \\
\text { L3 and S1 } \\
\text { - Patients who require fixation surgery and have a life expectancy of } \\
2 \text { years or more } \\
\text { - Participants who voluntarily agree to study participation and sign } \\
\text { a written informed consent form } \\
\text { - Subjects who fully understand the details of a clinical study and those } \\
\text { who are cooperative }\end{array}$ & $\begin{array}{l}\text { - Patients who required fixation surgery and have } 3 \text { or more intervertebral } \\
\text { - } \text { discs } \\
\text { f Patients who have previously undergone the spinal fusion surgery to be } \\
\text { investigated in this clinical study, or those who received interbody fusion } \\
\text { - } \text { - Pating an anterior or posterior fixation technique } \\
\text { - Patients with infections on the fracture region, those with past medical } \\
\text { e history of pathologic fraction, and those with family history of metabolic } \\
\text { bone disease (e.g., Paget disease, osteodystrophy, and heterotopic } \\
\text { ossification) }\end{array}$ \\
\hline
\end{tabular}

radical discectomy was performed through a transforaminal approach. An experimental material (DBM gel, $1.5 \mathrm{~mL}$; rhBMP-2, $0.055 \mathrm{mg}$ ) or control material (DBM gel, $1.5 \mathrm{~mL}$ ) was injected inside the intervertebral body fusion cage (CAPSTONE PEEK; Medtronic, Minneapolis, MN, USA) and inserted in the center between Lumbar vertebrae. The cage of which all sides are blocked and of which the top and bottom are opened was used. After inserting the intervertebral body fusion cage, fill the empty space outside the cage with autologous bone graft. The intervertebral disc is fixed with the pedicle screw fixation

\section{Study endpoints}

In this clinical study was evaluated the fusion rate at 12,24 , and 48 weeks post-treatment, the change in 100-mm Visual analog scale (VAS), the change in Oswestry disability index (ODI) and SF-36 quality of life (QOL), and the presence or absence of major adverse events. For the fusion rate at each time point, an independent assessment was performed based on the computed tomography (CT) scan and X-ray film. Fusion on the CT scan was defined as an evidence of trabecular bone bridging at an intracompartmental site. Fusion on the X-ray film was defined as less than 5 degrees of angular motion on flexion and extension radiographs or the case where radiolucency lines, which exceed $50 \%$ of the upper or lower surface of the implant, with a width more than $2 \mathrm{~mm}$ not appear ${ }^{37)}$. For safety evaluation, the adverse device effects (ADEs) and serious adverse device effects (SADEs) were used as safety endpoints. Treatment-emergent adverse events (TEAEs) that occurred after use of the investigational medical device during the entire period of the clinical study were coded by system organ class (SOC) and preferred term (PT) levels of the Medical Dictionary for Regulatory Activities (MedDRA) version
21.0 (International Federation of Pharmaceutical Manufactures and Association [IFPMA], Geneva, Switzerland).

\section{Statistical analysis}

Data obtained from subjects in this clinical study were analyzed using full analysis set (FAS). Safety data were analyzed using a safety set. The safety set included all subjects who were treated with bone graft materials. A random table was generated using the SAS software. For the statistical analysis, a twosided test was performed at a significance level of $5 \%$. SAS ${ }^{\circledR}$ version 9.4 (SAS Institute, Cary, NC, USA) was used for all statistical analyses. Continuous data were presented as the number of subjects, mean, standard deviation, and median. Categorical data were expressed as the frequency and percentage. According to whether data comply with a normal distribution, a two sample t-test or Wilcoxon's rank sum test was used to compare the changes from baseline in continuous variables at the last site visit between groups. According to whether data meet the assumption that the percentage of cells with an expected frequency of less than 5 is over 20\%, a Pearson's chi-square test or Fisher's exact test was performed to analyze the rate of change from normal results at baseline to abnormal results at the last site visit. Descriptive statistics were used to compare the change from the baseline in continuous variables at the last site visit within group. A paired t-test or Wilcoxon's signed rank test was performed according to whether data meet the assumption of normality.

\section{RESULTS}

\section{Study population}

All randomized subjects were treated with DBM gel with 
Table 2. Demographic information and baseline characteristics

\begin{tabular}{|c|c|c|c|}
\hline Parameter & DBM gel with rhBMP-2 $(n=40)$ & DBM gel $(n=36)$ & $p$-value \\
\hline Sex, M/F & 23/17 (57.50/42.50) & 19/17 (52.78/47.22) & $0.6793^{*}$ \\
\hline Age (years) & $64.03(10.63)$ & $62.67(9.32)$ & $0.5573^{\dagger}$ \\
\hline Height (cm) & $162.13(7.89)$ & $162.75(10.10)$ & $0.7633^{\dagger}$ \\
\hline Weight (kg) & $63.77(8.25)$ & $69.20(11.84)$ & $0.0251^{\dagger}$ \\
\hline $\mathrm{BMI}\left(\mathrm{kg} / \mathrm{m}^{2}\right)$ & $24.27(2.73)$ & $26.16(4.19)$ & $0.0243^{\dagger}$ \\
\hline BMD, T-score & $-0.55(1.38)$ & $-0.43(1.58)$ & $0.7274^{\dagger}$ \\
\hline Smoker & $25 / 15(62.50 / 37.50)$ & $25 / 11(69.44 / 30.55)$ & $0.6920^{\ddagger}$ \\
\hline Drug abuse & $40 / 0(100.00 / 0.00)$ & $36 / 0(100.00 / 0.00)$ & NA \\
\hline Level affected by DDD & 40 & 36 & $0.3214^{\ddagger}$ \\
\hline L3-L4 & $3(7.50)$ & $5(13.89)$ & \\
\hline$\llcorner 4-\lfloor 5$ & $18(45.00)$ & $10(27.78)$ & \\
\hline L5-S1 & $4(10.00)$ & $4(11.11)$ & \\
\hline L3-L4 \& L4-L5 & $10(25.00)$ & $8(22.22)$ & \\
\hline L4-L5 \& L5-S1 & $4(10.00)$ & $9(25.00)$ & \\
\hline$L 3-\lfloor 4 \& L 4-L 5$ \& L5-S1 & $1(2.50)$ & $0(0.00)$ & \\
\hline
\end{tabular}

Values are presented as $\mathrm{n} / \mathrm{N}(\%)$ or number (\%). *A Pearson's chi-square test was used for comparison between groups in categorical variables. ${ }^{\dagger} \mathrm{A}$ twosample t-test was used for comparison between groups in continuous variables. ${ }^{\ddagger} A$ Fisher's exact test was used for comparison between groups in categorical variables. DBM : demineralized bone matrix, rhBMP-2 : recombinant human bone morphogenetic protein-2, M : male, F : female, BMI : body mass index, BMD : bone mineral density, NA : not applicable, DDD : degenerative disc disease, N : number of observed subjects, number of subjects corresponding to each parameter

\section{Study endpoints}

In the FAS analysis, the fusion rate at 12-week post-treatment was $73.68 \%$ in the experimental group and $58.82 \%$ in the control group. The fusion rate at 24 - and 48 -week posttreatment was $72.22 \%$ and $82.86 \%$ in the experimental group and $78.79 \%$ and $78.13 \%$ in the control group. The change from baseline in the 100-mm VAS pain scoring, the experimental group showed $-45.45 \pm 27.84 \mathrm{~mm}$ at 12 weeks, $-45.31 \pm$ $26.79 \mathrm{~mm}$ at 24 weeks, and $-48.00 \pm 26.07 \mathrm{~mm}$ at 48 weeks. The control group showed $-36.97 \pm 31.78 \mathrm{~mm}$ at 12 weeks, $-43.39 \pm$ $27.81 \mathrm{~mm}$ at 24 weeks, and $-50.47 \pm 23.38 \mathrm{~mm}$ at 48 weeks. There were significant difference at 12,24 , and 48 weeks compared to the baseline of VAS scores within each group $(p<0.0001)$. The change from baseline in ODI QOL scoring, the experimental group showed $-20.34 \pm 19.99$ points at 12 weeks, $-22.96 \pm 17.11$ points at 24 weeks, and $-25.11 \pm 21.35$ points at 48 weeks. The control group showed $-18.62 \pm 22.90$ points at 12 weeks, $-20.81 \pm 20.35$ points at 24 weeks, and -25.36 \pm 18.82 points at 48 weeks. There were significant difference at 12,24 , and 48 weeks compared to the baseline of ODI QOL scores within each group $(p<0.0001)$ (Table 3).
As a result of the SF-36 QOL scores, there were no significant differences between two groups. The changes from baseline in SF-36 physical functioning, role-physical, bodily pain, vitality, social functioning, mental health, and physical component summary QOL scores at 12, 24, and 48 weeks showed a significant difference within each group except for general health $(\mathrm{GH})$, role-emotional (RE), and mental component summary (MCS) domains. The change from baseline in SF-36 GH QOL scoring, the experimental group showed 4.62 \pm 7.90 points at 12 weeks, $4.42 \pm 8.13$ points at 24 weeks, and $2.85 \pm$ 10.00 points at 48 weeks. The control group showed 3.90 \pm 9.01 points at 12 weeks, $3.93 \pm 8.14$ points at 24 weeks, and $3.87 \pm 8.06$ points at 48 weeks. There was a significant difference within each group at 12 and 24 weeks ( $p=0.0009, p=0.0025)$, but not at 48 weeks. The change from baseline in SF-36 RE QOL scoring, the experimental group showed $5.93 \pm 18.60$ points at 12 weeks, $8.21 \pm 16.12$ points at 24 weeks, and $9.44 \pm 17.87$ points at 48 weeks. The control group showed $7.43 \pm 19.31$ points at 12 weeks, $9.89 \pm 19.02$ points at 24 weeks, and $14.46 \pm 18.08$ points at 48 weeks. Within-group difference was not significant at 12 weeks, but it was significant at 24 and 48 weeks $(p=0.0004$, 
Table 3. Post-treatment fusion rate, 100-mm VAS pain and ODI QOL scores (based on the FAS population)

\begin{tabular}{|c|c|c|c|}
\hline & DBM gel with rhBMP-2 $(n=40)$ & DBM gel $(n=35)$ & Treatment difference $p$-value \\
\hline \multicolumn{4}{|l|}{ Fusion rate } \\
\hline Fusion rate at 12 weeks & 38 & 34 & \\
\hline Fusion & $28(73.68)$ & $20(58.82)$ & $0.1817^{*}$ \\
\hline Non-fusion & $10(26.32)$ & $14(41.18)$ & \\
\hline Fusion rate at 24 weeks & 36 & 33 & \\
\hline Fusion & $26(72.22)$ & $26(78.79)$ & $0.5272^{*}$ \\
\hline Non-fusion & $10(27.78)$ & $7(21.21)$ & \\
\hline Fusion rate at 48 weeks & 35 & 32 & \\
\hline Fusion & $29(82.86)$ & $25(78.13)$ & $0.6247^{*}$ \\
\hline Non-fusion & $6(17.14)$ & $7(21.88)$ & \\
\hline \multicolumn{4}{|l|}{ 100-mm VAS pain scores } \\
\hline Baseline & $72.08 \pm 16.45(n=40)$ & $74.43 \pm 13.90(n=35)$ & \\
\hline 12 weeks & $26.11 \pm 20.60(n=38)$ & $37.56 \pm 27.15(n=34)$ & \\
\hline 24 weeks & $25.47 \pm 21.96(n=36)$ & $31.00 \pm 20.74(n=33)$ & \\
\hline 48 weeks & $22.26 \pm 19.92(n=35)$ & $24.50 \pm 18.12(n=32)$ & \\
\hline 12 weeks-baseline & $-45.45 \pm 27.84(n=38)$ & $-36.97 \pm 31.78(n=34)$ & \\
\hline$p$-value & $<0.0001^{\dagger}$ & $<0.0001^{\dagger}$ & $0.2316^{\ddagger}$ \\
\hline 24 weeks-baseline & $-45.31 \pm 26.79(n=36)$ & $-43.39 \pm 27.81(n=33)$ & \\
\hline$p$-value & $<0.0001^{\dagger}$ & $<0.0001^{\dagger}$ & $0.7721^{\ddagger}$ \\
\hline 48 weeks-baseline & $-48.00 \pm 26.07(n=35)$ & $-50.47 \pm 23.38(n=32)$ & \\
\hline$p$-value & $<0.0001^{\dagger}$ & $<0.0001^{\dagger}$ & $0.6856^{\ddagger}$ \\
\hline \multicolumn{4}{|l|}{ ODI QOL scores } \\
\hline Baseline & $46.91 \pm 16.65(n=40)$ & $51.03 \pm 13.16(n=35)$ & \\
\hline 12 weeks & $26.41 \pm 16.44(n=38)$ & $33.08 \pm 18.37(n=34)$ & \\
\hline 24 weeks & $24.61 \pm 16.22(n=36)$ & $30.77 \pm 16.56(n=33)$ & \\
\hline 48 weeks & $22.28 \pm 17.13(n=35)$ & $26.33 \pm 17.19(n=32)$ & \\
\hline 12 weeks-baseline & $-20.34 \pm 19.99(n=38)$ & $-18.62 \pm 22.90(n=34)$ & \\
\hline$p$-value & $<0.0001^{\dagger}$ & $<0.0001^{\dagger}$ & $0.7349^{\ddagger}$ \\
\hline 24 weeks-baseline & $-22.96 \pm 17.11(n=36)$ & $-20.81 \pm 20.35(n=33)$ & \\
\hline$p$-value & $<0.0001^{\dagger}$ & $<0.0001^{\dagger}$ & $0.6346^{\ddagger}$ \\
\hline 48 weeks-baseline & $-25.11 \pm 21.35(n=35)$ & $-25.36 \pm 18.82(n=32)$ & \\
\hline$p$-value & $<0.0001^{\dagger}$ & $<0.0001^{\dagger}$ & $0.9598^{\ddagger}$ \\
\hline
\end{tabular}

Values are presented as mean \pm standard deviation or number (\%). *A Pearson's chi-square test was used for comparison between groups. ${ }^{\dagger} \mathrm{A}$ paired t-test was used for within-group comparison. ${ }^{\ddagger} A$ two sample t-test was used for between-group comparison. VAS : Visual analog scale, ODI : Oswestry disability index, QOL : quality of life, FAS : full analysis set, DBM : demineralized bone matrix, rhBMP-2 : recombinant human bone morphogenetic protein-2, $n$ : number of observed subjects, number of subjects corresponding to each category

$p=0.0043)$. The change from baseline in SF-36 MCS QOL scoring, the experimental group showed $2.93 \pm 14.15$ points at 12 weeks, $5.76 \pm 12.69$ points at 24 weeks, and $4.06 \pm 13.34$ points at 48 weeks. The control group showed $5.83 \pm 12.37$ points at 12 weeks, $7.77 \pm 14.28$ points at 24 weeks, and $8.18 \pm 14.98$ points at
48 weeks. Within-group difference was not significant at 12 and 48 weeks, but it was significant at 24 weeks $(p=0.0014)$ (Table 4).

As a result of identifying the presence or absence of major adverse events such as osteolysis, heterotopic bone formation, 


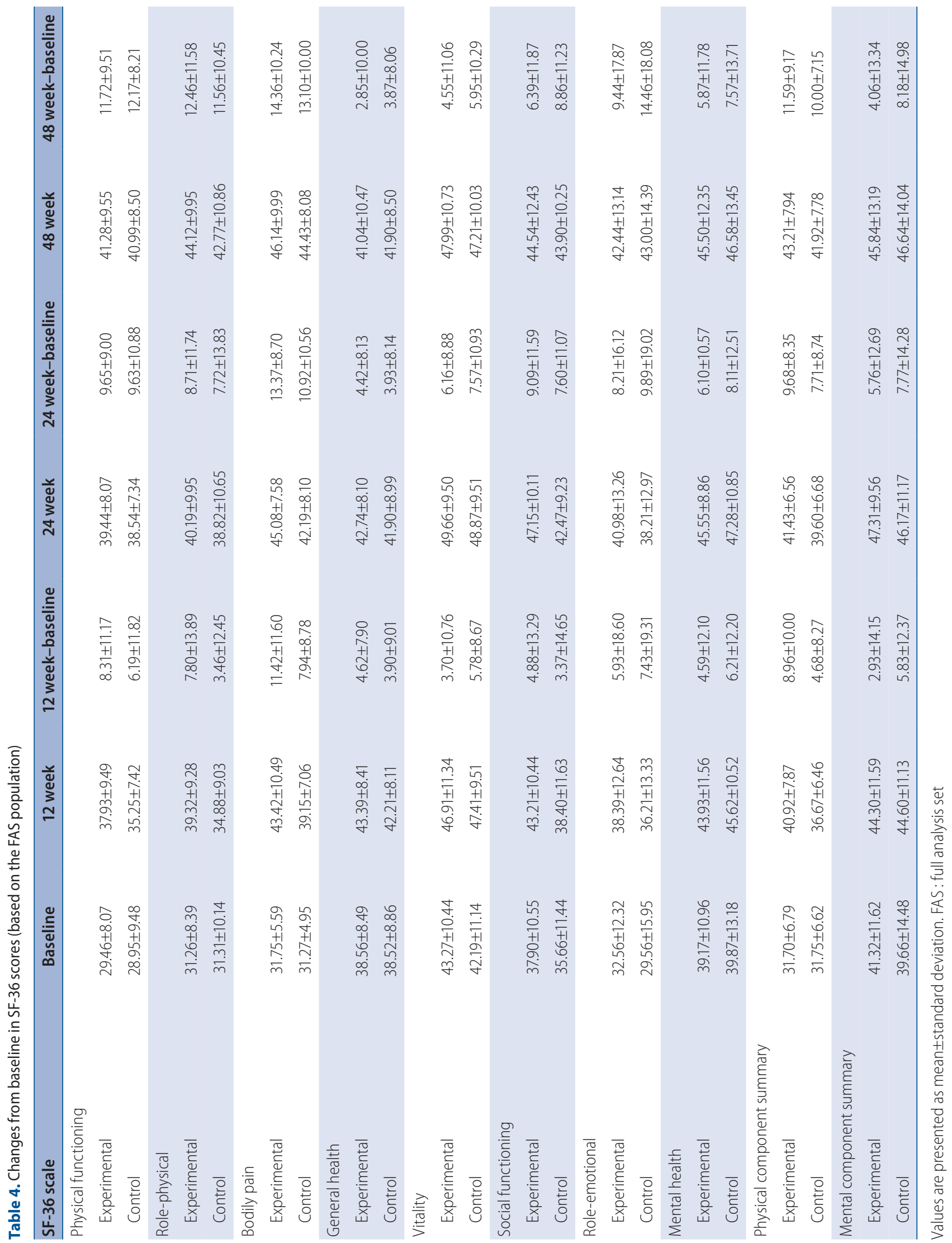


J Korean Neurosurg Soc 64 | July 2021

Table 5. Incidence rate of ADEs and SADE (based on the FAS population)

\begin{tabular}{|c|c|c|c|}
\hline & DBM gel with rhBMP-2 $(n=40)$ & DBM gel $(n=35)$ & $p$-value \\
\hline $\mathrm{ADE}$ & $6(15.00)$ & $8(22.86)$ & $0.3836^{*}$ \\
\hline Mild & $5(12.50)$ & $6(17.14)$ & \\
\hline Moderate & $0(0.00)$ & $2(5.71)$ & \\
\hline Severe & $1(2.50)$ & $0(0.00)$ & \\
\hline SADE related to the investigational device & $2(5.00)$ & $3(8.57)$ & $0.6594^{\dagger}$ \\
\hline \multicolumn{4}{|l|}{ Relatedness to the investigational device } \\
\hline Unrelated & $0(0.00)$ & $0(0.00)$ & \\
\hline Unlikely & $5(12.50)$ & $8(22.86)$ & \\
\hline Possible & $1(2.50)$ & $0(0.00)$ & \\
\hline Probable & $0(0.00)$ & $0(0.00)$ & \\
\hline Certain & $0(0.00)$ & $0(0.00)$ & \\
\hline \multicolumn{4}{|l|}{ SOCPT } \\
\hline General disorders and administration site conditions & $2(5.00)$ & $3(8.57)$ & \\
\hline Pyrexia & $2(5.00)$ & $1(2.86)$ & \\
\hline Chest discomfort & $0(0.00)$ & $1(2.86)$ & \\
\hline Pain & $0(0.00)$ & $1(2.86)$ & \\
\hline Nervous system disorders & $3(7.50)$ & $0(0.00)$ & \\
\hline Hypesthesia & $1(2.50)$ & $0(0.00)$ & \\
\hline Paresthesia & $1(2.50)$ & $0(0.00)$ & \\
\hline Transient peripheral paralysis & $1(2.50)$ & $0(0.00)$ & \\
\hline Musculoskeletal and connective tissue disorders & $1(2.50)$ & $1(2.86)$ & \\
\hline Osteoarthritis & $0(0.00)$ & $1(2.86)$ & \\
\hline Spondylitis & $1(2.50)$ & $0(0.00)$ & \\
\hline Renal and urinary disorders & $0(0.00)$ & $2(5.71)$ & \\
\hline Nephropathy toxic & $0(0.00)$ & $1(2.86)$ & \\
\hline Neurogenic bladder & $0(0.00)$ & $1(2.86)$ & \\
\hline Investigations & $0(0.00)$ & $1(2.86)$ & \\
\hline Liver function analyses & $0(0.00)$ & $1(2.86)$ & \\
\hline Psychiatric disorders & $1(2.50)$ & $0(0.00)$ & \\
\hline Insomnia & $1(2.50)$ & $0(0.00)$ & \\
\hline Skin and subcutaneous tissue disorders & $0(0.00)$ & $1(2.86)$ & \\
\hline Urticaria & $0(0.00)$ & $1(2.86)$ & \\
\hline SADE & $2(5.00)$ & $3(8.57)$ & $0.6446^{\ddagger}$ \\
\hline General disorders and administration site conditions & $1(2.50)$ & $1(2.86)$ & \\
\hline Chest discomfort & $0(0.00)$ & $1(2.86)$ & \\
\hline Pyrexia & $1(2.50)$ & $0(0.00)$ & \\
\hline Musculoskeletal and connective tissue disorders & $1(2.50)$ & $1(2.86)$ & \\
\hline Osteoarthritis & $0(0.00)$ & $1(2.86)$ & \\
\hline Spondylitis & $1(2.50)$ & $0(0.00)$ & \\
\hline Renal and urinary disorders & $0(0.00)$ & $1(2.86)$ & \\
\hline Neurogenic bladder & $0(0.00)$ & $1(2.86)$ & \\
\hline
\end{tabular}

Values are presented as number (\%). *A Pearson's chi-square test was used for between-group comparison. ${ }^{\dagger}$ A Fisher's exact test was used for between-group comparison. ${ }^{\ddagger}$ Fisher's exact test was used for between-group comparison. ADEs : adverse device effects, SADEs : serious adverse device effects, FAS : full analysis set, DBM : demineralized bone matrix, rhBMP-2 : recombinant human bone morphogenetic protein-2, $\mathrm{n}$ : number of observed subjects number of subjects corresponding to each category, SOC : system organ class, PT : preferred term 
and malignant tumor presentation, there were no subjects with major adverse events.

\section{Safety}

The incidence rate of ADEs was $15.00 \%$ in the experimental group and $22.86 \%$ in the control group. There was no significant difference between the two groups in the incidence rate of ADEs ( $p=0.3836$ ). The incidence rate of ADEs classified by severity was $12.50 \%$ for mild and $2.50 \%$ for severe in experimental group and $17.14 \%$ for mild and $5.71 \%$ for moderate in control group. The incidence rate of SADEs in experimental and control groups was $5.00 \%$ and $8.57 \%$, respectively. There was no significant difference between the two groups in the incidence rate of SADEs ( $p=0.6594)$. For ADEs classified by the MedDRA SOC level, the most common ADE was 'nervous system disorders' (7.50\%) followed by 'general disorders and administration site conditions' (5.00\%) and 'musculoskeletal and connective tissue disorders' and 'psychiatric disorders' (2.50\%) in the experimental group. In control group, the most frequent $\mathrm{ADE}$ was 'general disorders and administration site conditions' (8.57\%), followed by 'renal and urinary disorders' (5.71\%), and 'musculoskeletal and connective tissue disorders', 'investigations' and 'skin and subcutaneous tissue disorders' (2.86\%). For ADEs classified by the MedDRA PT level, 'pyrexia' (5.00\%) was the most common $\mathrm{ADE}$ in the experimental group, followed by 'hypesthesia', 'paresthesia', 'transient peripheral paralysis', 'spondylitis' and 'insomnia' (2.50\%, respectively). ADEs reported in control group included 'pyrexia', 'chest discomfort', 'pain', 'osteoarthritis', 'nephropathy toxic', 'neurogenic bladder', 'liver function analyses' and 'urticaria' (2.86\%). In causal relationship by the TEAE was 'possibly related' $(2.50 \%)$, possible not related (12.50\%) and 'definitely not related' $(87.50 \%)$ in the experimental group.

TEAE reported in the control group, possible not related (22.86\%) and 'definitely not related' (74.29\%). For SADE classified by the MedDRA SOC and PT level, 'pyrexia' and 'spondylitis' in the experimental group were $2.50 \%$. SADE reported in the control group included 'chest discomfort', 'osteoarthritis' and 'neurogenic bladder' (2.86\%) (Table 5). 'Spondylitis' was evaluated as "Possibly related" according to the causality assessment and was reported as an unexpected SADE. This event was classified as "Severe" in severity and was resolved after inpatient treatment and follow-up observations. All SADEs, other than 'spondylitis', were evaluated as "Unlikely related”. 'Osteoarthritis' classified as "Moderate” was observed in the left knee. 'Pyrexia' classified as "Mild" is a commonly reported adverse event that may occur due to post-operative infections. 'Chest discomfort' classified as "Mild" was considered to result from past medical history of atrial fibrillation although cardiological abnormalities were not observed. All SADEs described above were resolved after medical treatment.

\section{DISCUSSION}

This clinical study was conducted to evaluate the efficacy and safety of DBM gel with rhBMP-2 versus DBM gel used during the TLIF procedure. The fusion rate in experimental group was $73.68 \%$ and that in control group was $58.82 \%$. But there was no significant difference between the two groups.

In results of fusion rate at 24 weeks after implantation of DBM gel with rhBMP-2, the fusion rate was $72.22 \%(26 / 36$ patients), which tended to decrease slightly compared to the 12 week fusion rate of $73.68 \%$ (28/38 patients). The number of fused patients decreased because two patients who were determined to be fused at 12 weeks were dropped out at 24 weeks. However, the fusion rate at 48 weeks was $82.86 \%$ (29/35 patients), and it was confirmed that the fusion rate gradually increased. The 48 week fusion rate of control group was 78.13\% (25/32 patients), which tended to decrease slightly compared to the 24 week fusion rate of $78.79 \%$ (26/33 patients). The number of fused patients decreased because one patients who were determined to be fused at 24 weeks were dropped out at 48 weeks.

The Change from baseline in 100-mm VAS pain scores at 12,24 , and 48 weeks post-treatment showed no significant differences between experimental and control groups, but showed a significant difference within each group. There were no significant differences between the two groups in the ODI and SF-36 QOL scores at all post-treatment time points. However, the ODI QOL scores gradually decreased until 48 weeks post-treatment, showing a tendency of improvement in functions of the spine during normal activities. The SF-36 scores for all domains after treatment with DBM gel with rhBMP-2 increased, suggesting an increase in the QOL.

There was no adverse event such as osteolysis, heterotopic bone formation and malignant tumor in this study. The incidence rate of ADEs did not show a significant difference be- 
tween two groups. According to the causality assessment, all ADEs, other than 1 ADE evaluated as "Possibly related" to DBM gel with rhBMP-2, were evaluated as "Unlikely related" and then were resolved.

The other previous published clinical studies of rhBMP-2 were evaluated by showing high bone fusion rate of the spine. However, there have been also the case reports concerning adverse safety effects by using a high dose of rhBMP-2 $2^{8-12,20,25,29,32,33)}$. A recent study addressed that a high dose of rhBMP-2 cause the imbalance of transforming growth factor- $\beta$ signalling, thereby leading to cancer development ${ }^{6)}$. Although the direct evidence of carcinogenesis associated with rhBMP-2 is not identified, many considerations about a high dose of rhBMP-2, carrier, and theoretical carcinogenesis have been studied $^{12)}$. Therefore, it is important to consider not only a dose but also the design of the grafting materials including expected side effects. The DBM gel with rhBMP-2 for the clinical use was designed to overcome safety issues about the side effect as well as effectiveness about high bone fusion rate. By applying a reduced dose of rhBMP-2, we combined it with DBM gel, which has been well-known as a grafting material which has osteo-conductive and osteo-inductive effects. Regarding the effects of rhBMP-2, we did not see any significant difference of the spinal fusion rate comparing the patient groups between the DBM gel and rhBMP-2 DBM gel implanted at 48 weeks follow-up.

We did not see any valuable effectiveness on rhBMP-2 use for 48 weeks. However, we did see safety after using rhBMP-2 during the initial stage. And even in the initial stage, the DBM gel with rhBMP-2 group showed higher fusion rate which shows the possibility for successful rehabilitation effect at the earlier stage. This first clinical study about DBM gel with rhBMP-2 is, at least, good to know about safety by using the new design of rhBMP-2 included bone grafting material. So, we think that the follow up at the early time points is meaningful for the possibilities about better rehabilitation effects without no adverse effects. Although it is believed that rhBMP-2 use may promote bone fusion, clinical results indicate that surgeon should carefully consider using rhBMP-2 as an adjuvant for lumbar fusion in patients who are not at high risk of nonunion. In addition, rhBMP-2 is relatively high cost, so it is necessary to choose carefully when performing spine fusion surgery.

There were several limitations to this study. First, this clini- cal trial was conducted for 48 weeks, but 2 year follow-up is required to reliably evaluate spinal fusion and stability. Considering the duration, the 48 weeks might be too short to precisely evaluate fusion status and can be lead to underestimated. Second, considering the safety of the side effects of rhBMP-2, the concentration of rhBMP-2 in the experimental group was lowered, but the factors that may affect bone fusion were not considered. Therefore, when designing a clinical trial, the impact of rhBMP-2 concentrations should be considered.

\section{CONCLUSION}

This study demonstrated that the fusion rates of DBM gel group and DBM gel with rhBMP-2 group were not significantly different. But, this study provides knowledge regarding the earlier postoperative effect of rhBMP-2 containing DBM gel and also supports the idea that the longer term follow-up results are essential to confirm the safety and effectiveness.

\section{CONFLICTS OF INTEREST}

Seung Hwan Yoon has been editorial board of JKNS since November 2016. He was not involved in the review process of this original article. No potential conflict of interest relevant to this article was reported.

\section{INFORMED CONSENT}

Informed consent was obtained from all individual participants included in this study.

\section{AUTHOR CONTRIBUTIONS}

\author{
Conceptualization : SJH, YH \\ Data curation : SJH, SHY, JHK, JKO, YH \\ Formal analysis : CHL, JJS, JK \\ Funding acquisition : SJH, SHY, JHK, JKO, YH \\ Methodology : SJH, SHY, JHK, JKO, YH \\ Project administration : $\mathrm{YH}$ \\ Visualization: SJH
}


Writing - original draft : $\mathrm{SJH}$

Writing - review \& editing: $\mathrm{YH}$

\section{ORCID}

Seung-Jae Hyun https://orcid.org/0000-0003-2937-5300

Seung Hwan Yoon https://orcid.org/0000-0003-0558-2313

Joo Han Kim ～https://orcid.org/0000-0002-4747-9763

Jae Keun Oh https://orcid.org/0000-0001-5127-2661

Chang-Hyun Lee https://orcid.org/0000-0003-0134-2101

Jun Jae Shin https://orcid.org/0000-0002-1503-6343

Jiin Kang https://orcid.org/0000-0001-7349-4329

Yoon $\mathrm{Ha} \quad$ https://orcid.org/0000-0002-3775-2324

\section{- Acknowledgements}

This research was supported by a grant of the Korea Health Technology R\&D Project through the Korea Health Industry Development Institute, funded by the Ministry of Health \& Welfare, Republic of Korea (grant number : HI16C0751).

\section{References}

1. Boden SD, Kang J, Sandhu H, Heller JG : Use of recombinant human bone morphogenetic protein-2 to achieve posterolateral lumbar spine fusion in humans: a prospective, randomized clinical pilot trial: 2002 Volvo Award in clinical studies. Spine (Phila Pa 1976) 27 : 26622673, 2002

2. Bormann N, Schwabe P, Smith MD, Wildemann B : Analysis of parameters influencing the release of antibiotics mixed with bone grafting material using a reliable mixing procedure. Bone 59 : 162-172, 2014

3. Brantigan JW, Steffee AD, Geiger JM : A carbon fiber implant to aid interbody lumbar fusion. Mechanical testing. Spine (Phila Pa 1976) 16(6 Suppl) : S277-S282, 1991

4. Brekke JH, Toth JM : Principles of tissue engineering applied to programmable osteogenesis. J Biomed Mater Res 43 : 380-398, 1998

5. Burkus JK, Gornet MF, Dickman CA, Zdeblick TA : Anterior lumbar interbody fusion using rhBMP-2 with tapered interbody cages. J Spinal Disord Tech 15 : 337-349, 2002

6. Carragee EJ, Chu G, Rohatgi R, Hurwitz EL, Weiner BK, Yoon ST, et al. : Cancer risk after use of recombinant bone morphogenetic protein-2 for spinal arthrodesis. J Bone Joint Surg Am 95 : 1537-1545, 2013

7. Chang HK, Huang M, Wu JC, Huang WC, Wang MY : Less opioid consumption with enhanced recovery after surgery transforaminal lumbar interbody fusion (TLIF): a comparison to standard minimally-invasive
TLIF. Neurospine 17 : 228-236, 2020

8. Chen NF, Smith ZA, Stiner E, Armin S, Sheikh H, Khoo LT : Symptomatic ectopic bone formation after off-label use of recombinant human bone morphogenetic protein-2 in transforaminal lumbar interbody fusion. J Neurosurg Spine $12:$ 40-46, 2010

9. Choudhry OJ, Christiano LD, Singh R, Golden BM, Liu JK : Bone morphogenetic protein-induced inflammatory cyst formation after lumbar fusion causing nerve root compression. J Neurosurg Spine 16 : 296-301, 2012

10. Cooper GS, Kou TD : Risk of cancer after lumbar fusion surgery with recombinant human bone morphogenic protein-2 (rh-BMP-2). Spine (Phila Pa 1976) 38 : 1862-1868, 2013

11. Deutsch $\mathrm{H}$ : High-dose bone morphogenetic protein-induced ectopic abdomen bone growth. Spine J 10 : e1-e4, 2010

12. Epstein NE : Basic science and spine literature document bone morphogenetic protein increases cancer risk. Surg Neurol Int 5(suppl 15) : S552-S560, 2014

13. Gitelman SE, Kobrin MS, Ye JQ, Lopez AR, Lee A, Derynck R : Recombinant Vgr-1/BMP-6-expressing tumors induce fibrosis and endochondral bone formation in vivo. J Cell Biol 126 : 1595-1609, 1994

14. Gruskin E, Doll BA, Futrell FW, Schmitz JP, Hollinger JO : Demineralized bone matrix in bone repair: history and use. Adv Drug Deliv Rev 64 : 1063-1077, 2012

15. Guerado $\mathrm{E}$, Fuerstenberg $\mathrm{CH}$ : What bone graft substitutes should we use in post-traumatic spinal fusion? Injury 42 Suppl 2 : S64-S71, 2011

16. Han B, Yang Z, Nimni M : Effects of moisture and temperature on the osteoinductivity of demineralized bone matrix. J Orthop Res 23 : 855861, 2005

17. Haws BE, Khechen B, Patel DV, Yoo JS, Guntin JA, Cardinal KL, et al. : Impact of iliac crest bone grafting on postoperative outcomes and complication rates following minimally invasive transforaminal lumbar interbody fusion. Neurospine 16 : 772-779, 2019

18. Katayama Y, Matsuyama Y, Yoshihara H, Sakai Y, Nakamura H, Imagama $S$, et al. : Clinical and radiographic outcomes of posterolateral lumbar spine fusion in humans using recombinant human bone morphogenetic protein-2: an average five-year follow-up study. Int Orthop 33 : 10611067, 2009

19. Kim DJ : Autogenous bone graft and bone substitutes. J Korean Soc Spine Surg 15 : 54-65, 2008

20. Lad SP, Bagley JH, Karikari IO, Babu R, Ugiliweneza B, Kong M, et al. : Cancer after spinal fusion: the role of bone morphogenetic protein. Neurosurgery $73:$ 440-449, 2013

21. Ma GW : Posterior lumbar interbody fusion with specialized instruments. Clin Orthop Relat Res (193) : 57-63, 1985

22. Massaad E, Fatima N, Kiapour A, Hadzipasic M, Shankar GM, Shin JH : Polyetheretherketone versus titanium cages for posterior lumbar interbody fusion: meta-analysis and review of the literature. Neurospine 17 : 125-135, 2020

23. May RD, Frauchiger DA, Albers CE, Hofstetter W, Gantenbein B : Exogenous stimulation of human intervertebral disc cells in 3-dimensional alginate bead culture with BMP2 and L51P: cytocompatibility and effects 
on cell phenotype. Neurospine $17: 77-87,2020$

24. McKay WF, Peckham SM, Badura JM : A comprehensive clinical review of recombinant human bone morphogenetic protein-2 (INFUSE bone graft). Int Orthop $31:$ 729-734, 2007

25. Mindea SA, Shih P, Song JK : Recombinant human bone morphogenetic protein-2-induced radiculitis in elective minimally invasive transforaminal lumbar interbody fusions: a series review. Spine (Phila Pa 1976) 34 : 1480-1484; discussion 1485, 2009

26. Mummaneni PV, Pan J, Haid RW, Rodts GE : Contribution of recombinant human bone morphogenetic protein-2 to the rapid creation of interbody fusion when used in transforaminal lumbar interbody fusion: a preliminary report. Invited submission from the Joint Section Meeting on Disorders of the Spine and Peripheral Nerves, March 2004. J Neurosurg Spine 1 : 19-23, 2004

27. Niederwanger $M$, Urist MR : Demineralized bone matrix supplied by bone banks for a carrier of recombinant human bone morphogenetic protein (rhBMP-2): a substitute for autogeneic bone grafts. J Oral Implantol 22 : 210-215, 1996

28. Overley SC, McAnany SJ, Anwar MA, Merrill RK, Lovy A, Guzman JZ, et al. : Predictive factors and rates of fusion in minimally invasive transforaminal lumbar interbody fusion utilizing rhBMP-2 or mesenchymal stem cells. Int J Spine Surg 13 : 46-52, 2019

29. Rihn JA, Patel R, Makda J, Hong J, Anderson DG, Vaccaro AR, et al. : Complications associated with single-level transforaminal lumbar interbody fusion. Spine J 9 : 623-629, 2009

30. Sampath TK, Maliakal JC, Hauschka PV, Jones WK, Sasak H, Tucker RF, et al. : Recombinant human osteogenic protein-1 (hOP-1) induces new bone formation in vivo with a specific activity comparable with natural bovine osteogenic protein and stimulates osteoblast proliferation and differentiation in vitro. J Biol Chem 267 : 20352-20362, 1992

31. Schmidmaier $G$, Herrmann $S$, Green J, Weber $T$, Scharfenberger $A$, Haas $N P$, et al. : Quantitative assessment of growth factors in reaming aspirate, iliac crest, and platelet preparation. Bone 39 : 1156-1163, 2006

32. Shahlaie K, Kim KD : Occipitocervical fusion using recombinant human bone morphogenetic protein-2: adverse effects due to tissue swelling and seroma. Spine (Phila Pa 1976) 33 : 2361-2366, 2008

33. Smucker JD, Rhee JM, Singh K, Yoon ST, Heller JG : Increased swelling complications associated with off-label usage of rhBMP-2 in the anterior cervical spine. Spine (Phila Pa 1976) 31 : 2813-2819, 2006

34. Takeda $\mathrm{M}$ : Experience in posterior lumbar interbody fusion: unicortical versus bicortical autologous grafts. Clin Orthop Relat Res (193) : 120-126, 1985

35. Urist MR : Bone: formation by autoinduction. Science $150: 893-899$, 1965

36. Urist MR, Strates $B S$ : Bone formation in implants of partially and wholly demineralized bone matrix. Including observations on acetone-fixed intra and extracellular proteins. Clin Orthop Relat Res 71 : 271-278, 1970

37. Villavicencio AT, Burneikiene S, Nelson EL, Bulsara KR, Favors M, Thramann J : Safety of transforaminal lumbar interbody fusion and intervertebral recombinant human bone morphogenetic protein-2. J Neurosurg Spine 3 : 436-443, 2005

38. Winn SR, Uludag H, Hollinger JO : Carrier systems for bone morphogenetic proteins. Clin Orthop Relat Res (367 Suppl) : S95-S106, 1999

39. Yan L, Chang Z, He B, Liu T, Wang X, Guo H, et al. : Efficacy of rhBMP-2 versus iliac crest bone graft for posterior C1-C2 fusion in patients older than 60 years. Orthopedics 37 : e51-e57, 2014 